Trab. Ling. Aplic., Campinas, 50(1): 205-217, Jan./Jun. 2011

\title{
A TRADUÇÃO NO ENSINO DE LÍNGUAS: VOCABULÁRIO, GRAMÁTICA, PRAGMÁTICA OU CONSCIÊNCIA CULTURAL?
}

\author{
TRANSLATION IN FOREIGN LANGUAGE TEACHING: VOCABULARY, \\ GRAMMAR, PRAGMATICS OR CULTURAL CONSCIOUSNESS?
}

\author{
RUTH BOHUNOVSKY*
}

\begin{abstract}
RESUMO: A partir de uma leitura crítica de trabalhos acadêmicos do contexto brasileiro que versam sobre as possíveis vantagens e desvantagens do uso da tradução no ensino de línguas estrangeiras, discutimos diversos usos do termo tradução nesse âmbito, atualmente. Num primeiro momento, concentramos nossa atenção em aspectos predominantemente metodológicos. Propomos uma possível divisão em quatro usos metodológicos da tradução no ensino de línguas estrangeiras. Depois, procuramos argumentar que vários trabalhos que abordam a questão da tradução no contexto de ensino de línguas estrangeiras deixam de fazer uma reflexão teórica aprofundada sobre essa atividade e, consequentemente, fundamentam sua argumentação num conceito de tradução enraizado no senso comum - e questionado há décadas por diversos estudiosos do assunto. Finalmente, sugerimos um diálogo mais intenso entre a área do ensino de línguas estrangeiras e os estudos da tradução.

Palavras-chave: Ensino de línguas estrangeiras, tradução, metodologia.
\end{abstract}

ABSTRACT: This paper presents an overview of some academic work carried out in the Brazilian context that comments on possible advantages and disadvantages of the use of translation in foreign language teaching. The paper brings up the discussion about different uses of the term translation. At first, we concentrate on methodological aspects and propose a division in four methodological uses of translation in foreign language teaching. Secondly, we try to show that some of the works that discuss the question of translation in foreign language teaching context do not make a serious theoretical reflection on the concept of translation itself. Consequently, their argumentation on this activity relies on a theoretical concept that is based on the common sense - and that has been criticized over decades by many translation studies theorists. Finally, we propose a dialogue between the academic areas of foreign language teaching and translation studies.

Keywords: foreign language teaching, translation, methodology.

\section{INTRODUÇÃO}

Depois de ter sido banida das salas de aula durante várias décadas, a tradução ${ }^{1}$ está "voltando" para o ensino de línguas estrangeiras. Essa tendência pode ser conferida tanto na constante presença de seções temáticas sobre o papel da tradução no ensino de línguas estrangeiras em congressos da área, quanto no número crescente de trabalhos acadêmicos

*UFPR, Curitiba, (PR), Brasil.ruth.bohunovsky@uol.com.br

${ }^{1}$ Ao me referir à tradução no presente trabalho, limito-me à tradução interlingual na definição de Roman Jakobson (1969) - em oposição à tradução intralingual e à tradução intersemiótica. 
que defendem a atividade tradutória em sala de aula durante o processo de ensino/ aprendizagem. No contexto brasileiro, podem ser citados os trabalhos de Romanelli (2006), Welker (2004), Hargreaves (2004), Checchia (2002) e Hinojosa e Lima (2008), entre outros. Embora esses trabalhos abordem a temática a partir de diferentes pontos de vista, há entre eles um elo comum: a tradução que ocorre hoje em dia em sala de aula não é - ou não deve ser - a mesma que marcava o Método de Gramática e Tradução, quando estava atrelada exclusivamente a propósitos gramaticais. Cabe então a seguinte pergunta: que tradução é essa da qual se fala hoje em dia e que deve "voltar" para as salas de aula? Se ela é diferente, por que então se fala em retorno? Recorrer à tradução no ensino de uma língua estrangeira significa usar a língua materna para explicar termos ou expressões desconhecidos? Ou significa praticar a "mediação linguística" como uma habilidade comunicativa à qual se refere, por exemplo, o Quadro Comum Europeu para o Ensino de Línguas? Tem algo a ver com a "competência cultural"? Ou se refere, talvez, à tradução escrita de textos literários?

Baseando-me em trabalhos acadêmicos - sobretudo dos autores acima mencionados -, procuro, na primeira parte deste trabalho, apontar os diversos usos do termo tradução no contexto do ensino de língua estrangeira no Brasil, atualmente. Argumento que alguns teóricos - apesar de todos eles enfatizarem a complexidade do termo - utilizam a palavra tradução num sentido muito amplo e nem sempre esclarecem a que formas de tradução estão se referindo em cada momento de sua argumentação. A partir dessa constatação, e com o objetivo de esclarecer os diversos procedimentos metodológicos que podem fazer uso da atividade tradutória, faço uma (possível) diferenciação da tradução, no âmbito do ensino de uma língua estrangeira, em quatro tipos, com base nos objetivos didáticos de seu emprego: o ensino/aprendizagem de vocabulário, a conscientização gramatical, a sensibilização para aspectos pragmáticos ou a competência linguístico-cultural.

Parto da premissa de Juliane House de que "para uma discussão fundada sobre o papel da tradução no ensino de línguas estrangeiras precisa-se, em primeiro lugar, de um fundamento teórico para a compreensão desse complexo processo interlingual" (HOUSE, 2001, p. 260). Assim, na segunda parte, discuto o trabalho de um dos autores acima citados que procura basear a sua argumentação numa reflexão teórica sobre a atividade tradutória. A partir do exposto, sugiro, finalmente, um diálogo mais amplo entre a área de ensino de línguas estrangeiras e os estudos da tradução.

\section{TRADUÇÃO E GRAMÁTICA}

A declaração de que a tradução, hoje, não deve ser aquela que foi no passado, referese geralmente, ao Método de Gramática e Tradução. Nesse método, a tradução de frases da língua materna para a língua estrangeira e vice-versa era a prática predominante em sala de aula. Além disso, vale lembrar que nesse contexto

[os] textos a serem traduzidos eram escolhidos de acordo com sua estrutura gramatical: isto é, seguiam uma progressão gramatical, e traduzir era o único caminho metodológico para preencher 
de significado os lexemas estrangeiros, para conhecer as estruturas estrangeiras no seu significado e era o único trabalho linguístico ativo durante a aula. (KÖNIGS, 2001, p. 956; grifos do autor)².

Os métodos e abordagens que surgiram ao longo do século passado têm, muitas vezes, rejeitado a tradução, como consequência do veto ao uso da língua materna no ensino de uma língua estrangeira (por exemplo, no âmbito do Método Direto). Nas últimas décadas, voltou-se a discutir as possíveis funções da tradução, porém não se faz mais referência à tradução como método, mas sim como forma de exercício ou de tarefa de aprendizagem dentro de um outro conceito metodológico. Nesse sentido, pode-se constatar, também, o movimento de um conceito de tradução não mais orientado pela avaliação, mas pela comunicação e pelo desenvolvimento de habilidades.

De todos os autores aos quais me refiro aqui, Herbert A. Welker é aquele cuja argumentação mais se aproxima dos pressupostos do Método de Gramática e Tradução. Crítico da abordagem comunicativa para o ensino de uma língua estrangeira num país diatante do(s) país(es) da língua-meta ${ }^{3}$, no qual os aprendizes tenham pouca ou nenhuma possibilidade de comunicação com um falante daquele(s) país(es), Welker acredita que "a organização do ensino segundo atos de fala é problemática" e defende uma progressão, sobretudo nos níveis iniciais, que seja ordenada segundo a gramática (2004, p. 3). Partindo dessa premissa, ele propõe a tradução de frases não autênticas, isoladas, sem inserção em qualquer contexto - mesmo se isso implicar a tradução de frases "com pouca probabilidade de ocorrerem numa situação de comunicação real” (2004, p. 8). O autor também vê a tradução como um recurso para a verificação do aprendizado. Tratar-se-ia, por exemplo, de frases como "Como vai? Meu pai é italiano, mas eu não falo italiano. Você gosta de ver televisão?” etc. (2004, p. 7). Para Welker, nos primeiros semestres do processo de ensino/aprendizagem, o único objetivo de tal exercício de tradução seria o controle do aprendizado de aspectos gramaticais. Passada a fase inicial, dever-se-ia iniciar então a "tradução interpretativa" (2004, p. 9), para a qual o "contexto" passaria a ganhar importância ${ }^{4}$.

Ao se ter em vista o domínio gramatical da língua estrangeira ou a comparação entre aspectos formais das línguas materna e estrangeira, a tradução de frases isoladas sem contexto pode certamente ser útil. Mas, como o próprio Welker admite, o processo de ensino/aprendizagem nunca se reduz à gramática - mesmo se ela for vista como base para a progressão. Além disso, repetindo as suas palavras, "pessoas que não são tradutores profissionais veem-se, às vezes, na situação de terem que traduzir - oralmente ou por escrito - tanto na direção LE $\rightarrow$ LM quanto na outra" (2004, p. 6). Ou seja, a tradução é vista por Welker não apenas como uma possibilidade para testar o aprendizado dos alunos, mas também como uma "quinta habilidade" (2004, p. 6) que, além de "ler, escrever,

\footnotetext{
${ }^{2}$ Esta tradução, assim como todas as outras de livros não traduzidos para o português, é minha.

${ }^{3}$ Welker - assim como a autora do presente trabalho - vem da área de alemão, mas acredita que suas ideias sobre o papel da tradução no ensino de línguas "sejam válidas para outras línguas” (WELKER 2004, p. 2).

${ }^{4}$ Ao longo do referido texto, Welker não deixa dúvida de que acredita que possa haver traduções para as quais o contexto não tem importância e que possam ser feitas sem "interpretação". Sem poder, neste momento, me aprofundar nesse aspecto, sugiro, no entanto, a leitura das discussões a respeito de linguagem e tradução por exemplo, em O signo desconstruido: Implicações para a tradução, a leitura e o ensino (ARROJO, 2003).
} 
compreender a fala e falar" (2004, p. 3), seria um dos objetivos do processo de ensino/ aprendizagem.

As frases de Welker poderiam, talvez, aparecer acompanhadas de algumas informações sobre um possível contexto. Assim, os alunos, além de se conscientizarem sobre diferenças estruturais e/ou gramaticais nas duas línguas, poderiam também se familiarizar, por exemplo, com os usos diferentes dos pronomes pessoais na língua materna e na língua estrangeira. Tratando-se de alemão, por exemplo, o uso inadequado ou a interpretação inadequada, mesmo por iniciantes, dos pronomes "Sie" ou "Du" terá consequências muito mais amplas do que a conjugação errada de um determinado verbo. Ou seja, no meu entender, não há muitos motivos para trabalhar, em sala de aula, exclusivamente com exercícios que pedem a tradução de frases isoladas, pois o ensino/ aprendizagem de aspectos gramaticais não exclui a abordagem de aspectos comunicativos e/ou culturais. Compartilho a convicção de Welker de que o ensino de uma língua estrangeira seja substancialmente diferente do ensino de uma segunda língua, mas não vejo a orientação exclusiva em aspectos gramaticais, nos primeiros semestres, como uma consequência lógica de tal convicção. Mesmo nos primeiros semestres, a tradução pode ter um lugar que abrange mais do que apenas a gramática e pode ser integrada no ensino de outras habilidades 5 .

\section{TRADUÇÃO E ABORDAGEM COMUNICATIVA}

Como já foi mencionado acima, Welker parte de uma posição teórica crítica em relação ao enfoque comunicativo no ensino de línguas estrangeiras. Além disso, sua argumentação sugere que ele considera essa abordagem não compatível com o uso da tradução em sala de aula (WELKER, 2004, p. 2-5). Cabe aqui um pequeno comentário sobre a relação entre a abordagem comunicativa e a tradução, pois há interpretações divergentes a respeito desse assunto. A leitura da dissertação de mestrado de Checchia evidencia como a crença de que ensinar "comunicativamente" implica, necessariamente, não recorrer à tradução está, de fato, fortemente disseminada entre professores de inglês no Brasil (2002, p. 8586). Romanelli também se refere à crença de que a "tradução foi definitivamente excluída e criticada pela 'Abordagem Comunicativa"” (2006, p. 3). E Hargreaves destaca que, "por muito tempo, era esperado dos professores que se identificassem como comunicativos e refutassem qualquer relação com o ensino de gramática e com a prática de tradução" $\left(2004\right.$, p. 8) ${ }^{6}$. Como deixam perceber suas argumentações, os autores aqui citados - com a exceção de Welker - não parecem compartilhar dessa crença, pois acreditam que uma abordagem comunicativa seja compatível com o uso da tradução em sala de aula. Tal perspectiva também é defendida por Hinojosa e Lima (2008), quando afirmam que, "nos inícios dos anos 80, a Abordagem Comunicativa (AC) surge como novo método de ensino de LE e passa a interferir de forma positiva no papel da tradução e sua prática em sala de aula" (2008, p. 5). Romanelli argumenta de maneira semelhante quando aponta

${ }^{5}$ Sobre a integração da tradução no ensino de outras habilidades, cf., por exemplo, Königs (2000, p. 11).

${ }^{6}$ Sobre essa crença, cf. também Azenha (2006, p. 159). 
o fato de que Widdowson (1979) - um dos precursores mais conhecidos do âmbito da Abordagem Comunicativa - "defende o uso da tradução, sobretudo quando uma língua estrangeira é estudada para fins específicos (instrumentais)" (ROMANELLI, 2006, p. 4). Essas citações deixam claro que a crença de que Comunicativismo e a prática da tradução sejam incompatíveis parece ter um fundamento teórico frágil, embora isso não signifique necessariamente uma redução da sua força, sobretudo entre os professores.

Partindo desse quadro, considero pertinente sugerir que, antes de se associar a prática tradutória a uma determinada abordagem metodológica, seria necessário perguntar o que exatamente se entende por tradução. Antes de entrar nessa questão, concentro-me agora numa pequena discussão sobre o uso da tradução, a partir de um ponto de vista meramente metodológico.

\section{O QUE É TRADUÇÃO NO ENSINO DE LÍNGUAS ESTRANGEIRAS?}

Voltando mais uma vez ao artigo de Welker, considero relevante mencionar o destaque que esse teórico dá à importância de uma diferenciação clara entre o uso da língua materna em sala de aula e o uso da tradução (2004, p. 4). De acordo com o autor, quando o professor traduz "palavras ou enunciados" (para efeitos de explicação), deveríamos nos referir a essa prática como "uso da língua materna" (2004, p. 4). Para Welker, a "tradução pedagógica restringe-se aos exercícios feitos pelos alunos" (2004, p. 4). Não se trata aqui de uma diferenciação "natural", que se daria por uma distinção fundamental entre esses dois usos da língua - como em qualquer teoria, essa distinção será sempre uma construção, entre outras possíveis, feita para se entender ou lidar melhor com aspectos da "realidade". Contudo, a diferenciação que esse autor faz parece ser útil de um ponto de vista metodológico, já que há diferenças bastante óbvias entre a explicitação de um novo termo na língua estrangeira via língua materna e um exercício tradutório feito pelos alunos visando a uma melhora da sua competência gramatical.

Diferentemente do trabalho de Welker, em outros artigos não encontramos essa busca por uma definição terminológica precisa. Ao defenderem o seu uso, vários autores se referem à "tradução" de um modo muito geral, o que não contribui para que haja uma reflexão mais específica sobre os diferentes papéis que essa atividade possa ter nesse contexto. Por exemplo, na sua dissertação de mestrado, Checchia (2002) se baseia, num certo momento, no conceito de tradução mais amplo possível, que considera qualquer tipo de comunicação como tradução:

\footnotetext{
A tradução é um processo natural, que sempre acontece, mesmo quando não explicitamente. Estamos sempre traduzindo, pois traduzir é entender o que está sendo comunicado. Como a linguagem varia de acordo com suas funções sociais, quando interpretamos as mensagens transmitidas, estamos traduzindo. (CHECCHIA, 2002, p. 81).
}

Logo depois dessa afirmação - que lembra discussões em outras áreas que, nas últimas décadas, recorreram à metáfora da tradução para se referir a diversas práticas interpretativas -, a autora resume os "benefícios" e as desvantagens que vários autores descrevem em relação ao possível uso da tradução em sala de aula (2002, p. 81). Se estamos "sempre" 
traduzindo, mesmo quando não nos damos conta, como podemos então discutir sobre as vantagens e desvantagens de um "possível" uso da tradução em sala de aula? Essa contradição se desfaz se distinguirmos entre diferentes usos do termo "tradução" que a autora faz no seu trabalho.

O uso contínuo de apenas um termo - "tradução" - para se referir a práticas didáticas diferentes perpassa a dissertação de Checchia. Assim, por exemplo, a autora menciona que a tradução pode ser "uma forma fácil e rápida de apresentar o significado de palavras", mas destaca, na mesma página, que "a tradução [...] tem que ser deixada para uma etapa em que o aluno já tenha alguma base", pois "[n]ão adianta querer fazer tradução sem vocabulário" (2002, p. 125). No primeiro caso, a tradução é vista como um meio para introduzir novo vocabulário; no segundo, como uma atividade para a qual o vocabulário seria o pressuposto. Na minha interpretação, entende-se aqui a tradução uma vez como semantização de termos novos, outra vez como habilidade. Apesar dos meus comentários críticos sobre o trabalho de Checchia, é obrigatório observar que se trata de uma pesquisa válida e interessante sobre crenças de professores de língua estrangeira em relação à tradução e que ilustra, assim como os outros trabalhos aqui citados, que o ato de traduzir em sala de aula pode apontar para práticas e posturas teóricas às vezes muito diferentes.

Levando em consideração as diversas interpretações possíveis do termo "tradução", pode-se concluir que nem todo mundo que argumenta em favor dessa atividade argumenta necessariamente a favor da mesma coisa. Assim como defender a escrita no ensino pode remeter desde o mero uso de papel e canetas em sala de aula até a escrita criativa em forma de projetos, vimos que defender a tradução permite também um leque amplo de possíveis interpretações: pode sugerir a simples aceitação do papel fundamental da língua materna até a tradução de textos literários ${ }^{7}$.

\section{DIFERENTES FUNÇÕES METODOLÓGICAS DA TRADUÇÃO NA PRÁTICA DO ENSINO}

Parto da premissa de que defender a tradução no contexto do ensino de línguas estrangeiras é uma afirmação muito geral para poder ser útil numa reflexão sobre como essa atividade poderia se dar na prática do ensino. A seguir, tento diferenciar quatro tipos de tradução, partindo das suas diferentes funções metodológicas e didáticas. Tal divisão em diferentes tipos de tradução - que podem apenas ser provisórios e sem limites claros - certamente não é conclusiva nem a única possível, porém me parece útil para se pensar

\footnotetext{
${ }^{7}$ Nesse sentido, entendo também que, ao citar Elsa R. Auerbach (1993) e Antonella Benucci (1994) como defensoras da tradução no ensino de inglês como língua estrangeira, Sérgio Romanelli (2006) se refere a duas autoras que talvez não tenham exatamente uma causa comum. De acordo com Romanelli, Auerbach sugere diferentes situações "para se utilizar a L1: negociação do programa e da aula, organização da sala de aula" e até mesmo a "discussão de assuntos interculturais" (2006, p. 6). Benucci, por sua vez, ao focalizar as vantagens da "análise contrastiva" para uma possível "reflexão sobre as relações da L2 com outros idiomas e culturas" vai muito além do mero uso da língua materna em determinadas ocasiões, como sugerido por Auerbach.
} 
sobre a prática da tradução no ensino de uma língua estrangeira, com a vantagem de evitar o uso indiscriminado do termo geral "tradução":

Em primeiro lugar, há momentos em que os autores fazem uso do termo "tradução" no sentido de uma prática para explicitar, de maneira efetiva, termos, expressões e estruturas desconhecidos da língua estrangeira (neste caso, pode-se falar simplesmente da tradução como meio para a semantização de vocabulário). Hoje, esse tipo de tradução é amplamente aceito como "inevitável” nos estágios iniciais do processo de ensino/ aprendizagem de uma língua estrangeira.

Um autor (da área de alemão como língua estrangeira) que diferencia claramente entre a semantização de vocabulário novo e a tradução propriamente dita é Wolfgang Butzkamm (2004). Em seu livro, ele propõe uma nova técnica para o ensino de línguas estrangeiras, que se caracteriza, sobretudo, pelo uso sistemático da língua materna, denominado "técnica sandwich" (Sandwich-Technik), isto é, a tradução de termos e expressões desconhecidos pelos aprendizes para a sua língua materna. De acordo com Butzkamm, trata-se de uma prática importante para alcançar aquilo que ele chama de "uso funcional de língua estrangeira" (funktionale Fremdsprachigkeit) (2004, p. 15). Cito a seguir um pequeno exemplo que ilustra sua proposta:

Professor: You've skipped a line. Você pulou uma linha. You've skipped a line.

Professor: I mean the last but one word. A penúltima palavra. The last but one word. (BUTZKAMM, 2004, p. 15).

Embora, certamente, trate-se aqui da tradução de expressões linguísticas ${ }^{8}$, Butzkamm diferencia claramente essa prática do uso da tradução propriamente dita em sala de aula (2004, p. 150-154). Por tradução propriamente dita, Butzkamm entende a tradução de textos ou passagens de textos, assim como a comparação de traduções já existentes, e define a "consciência linguística" como objetivo de tal trabalho tradutório integrado no ensino de uma língua estrangeira (2004, p. 150).

Um segundo tipo de uso da tradução seria aquele em que a tradução tem como objetivo didático principal a conscientização de estruturas gramaticais da língua estrangeira em contraste com as da língua materna. Esse tipo corresponderia - grosso modo - à "tradução pedagógica", na definição de Welker (2004). Embora aspectos pragmáticos e/ou culturais não possam ser totalmente desconsiderados ao se fazer uma "tradução pedagógica", entendo que esse tipo de tradução pode ser definido pela atenção especial dada aos aspectos formais da língua estrangeira. A fim de ilustrar esse tipo da tradução, cito aqui um exemplo da "versão interlinear" dado por Königs (2001, p. 957):

Voilà les deux messieurs qui

Da sind die zwei Männer die

s'installent à la terrasse d'un

sich niederlassen auf der Terrase eines

bistrot pour s'entretenir un peu.

Bistrots um sich zu unterhalten ein bißchen.

${ }^{8}$ Sobre a tradução como meio para a semantização de vocabulário, cf. também Nowak (2000). 
Em terceiro lugar, a tradução pode aparecer também como uma habilidade comunicativa que, ao lado de outras como "ler, escrever, compreender a fala e falar"

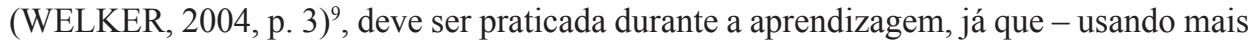
uma vez as palavras de Welker - "pessoas que não são tradutores profissionais veem-se às vezes na situação de terem que traduzir - oralmente ou por escrito - tanto na direção LE $\rightarrow$ LM quanto na outra" (2004, p. 6), independentemente se a língua é estudada como língua estrangeira ou como segunda língua. É sobretudo nessa forma comunicativopragmática de "mediação linguística", cujo enfoque é a oralidade, que a tradução é abordada e prevista no Quadro Comum Europeu para o Ensino de Línguas ${ }^{10}$. Por exemplo, está previsto que, no nível A1, o aprendiz de alemão deveria saber ajudar um turista que fale esse idioma numa loja em um país em que ela não seja língua oficial e saber informar, em alemão, os preços dos produtos. Já no nível mais avançado, C2, está previsto que o aprendiz saiba mediar uma conversa entre duas pessoas (das quais uma falante de alemão e outra falante da língua materna do aprendiz), sendo capaz de "transmitir todo o conteúdo e as informações de maneira completa, clara, fluente e estruturada" (GLABONIAT et al. 2005, p. 211 $)^{11}$. Apesar do uso concomitante de diversos conceitos de tradução em sua dissertação, em alguns trechos, Checchia não deixa dúvida de que defende esse conceito de tradução vista como uma "habilidade que depende das outras e as congrega" (2002, p. 124), e de que também acredita que se deve "preparar os alunos para usar uma habilidade de aplicação prática no seu dia-a-dia" (2002, p. 131).

Como já foi destacado por outros autores, a habilidade de "mediação linguística" não coincide com aquilo que geralmente entendemos como as habilidades tradutórias que um tradutor profissional deve desenvolver ao longo da sua formação ${ }^{12}$. Mas, a "mediação linguística" deve fazer parte do processo de ensino/aprendizagem de uma língua estrangeira, levando em consideração o número cada vez maior de contatos entre sujeitos de culturas diferentes, "nos quais nem todos os participantes possuem as condições linguísticas necessárias para a comunicação" (GNUTZMANN, 2000, p. 33). Concordo com Gnutzmann quando este afirma que "a precisão exagerada da expressão e a correção linguística não devem ser os princípios mais importantes desse tipo de competência de tradução oral", já que "em algumas situações de fala, a continuação da comunicação só vai ocorrer devido à tradução" (GNUTZMANN, 2000, p. 33).

Finalmente, traduzir durante o processo de ensino/aprendizagem de uma língua estrangeira é algo que pode se realizar também tendo como objetivo principal a "aprendizagem crítico-reflexiva", concentrando-se em aspectos linguísticos e/ou culturais. Um exemplo do uso da tradução nesse sentido é dado por Cássio Rodrigues que, referindo-

${ }^{9}$ Welker se refere a essas cinco habilidades. O Quadro Comum Europeu para o Ensino de Línguas, por exemplo, parte da divisão do processo de aprendizagem em quatro "atividades" (interação, produção, recepção e mediação linguística), e cada uma dessas "atividades" se constitui de duas "habilidades" (GLABONIAT et al. 2005, p. 58). No caso da "mediação linguística", essa "atividade" poderia se dar na forma escrita (tradução) ou oral (interpretação). Nos dois casos, é claro que se trata da tradução como habilidade comunicativa, não como meio para testar o conhecimento gramatical de alguém.

${ }^{10}$ Sobre a função da tradução prevista pelo Quadro Comum Europeu, cf. também Carvalho Neto (2007).

${ }^{11}$ Para uma discussão crítica sobre essa visão de tradução aparentemente neutra e não-interpretativa, indico, mais uma vez, Arrojo (2003).

${ }^{12}$ Cf., por exemplo, Checchia (2002, p. 126). 
se ao ensino de alemão no Brasil, discute a tradução como forma de exercício (vs. tradução como habilidade) a serviço da comparação linguística entre as duas línguas e da construção de conhecimento metalinguístico (2000, p. 25-32). De acordo com Rodrigues, ao fazer exercícios de tradução - preferencialmente em trabalho em grupos -, os aprendizes têm uma ótima oportunidade para refletirem sobre o processo do próprio aprendizado, comparando continuadamente as próprias hipóteses com aquelas dos colegas ${ }^{13}$.

Vários autores mencionam ainda que a tradução pode ter como objetivo uma melhor "competência cultural"14 dos aprendizes. Romanelli, por exemplo, afirma que "um uso adequado da tradução permitiria estabelecer um confronto cultural mais aprofundado entre as línguas e facilitaria o domínio da cultura-alvo pelo aluno" (2006, p. 4). Checchia dedica um subcapítulo ao tema "Conscientização cultural" e menciona o "ganho cultural" (2002, p. 114) para os alunos quando estes trabalham com tradução em sala de aula15.

O trabalho que mais se aprofunda nas relações entre língua, cultura e tradução é a dissertação de mestrado de Hargreaves (2004), intitulada Além da língua: tradução e consciência crítica de cultura no ensino de línguas estrangeiras. Hargreaves parte da premissa da "indivisibilidade" entre língua, cultura e tradução (2004, p. 34) e argumenta que "nenhum processo de aquisição ou aprendizagem de outra língua deverá tentar excluir um desses elementos" (2004, p. 34). De acordo com esse autor, "quando se fala em dificuldades da tradução ou de elementos intraduzíveis, trata-se, em geral, de aspectos culturais" (2004, p. 39). A seguir, cito uma passagem do trabalho de Hargreaves em que ele apresenta motivos a favor da tradução como meio para a "conscientização cultural" dos aprendizes:

[...] o contraste cultural gerado pela atividade de tradução é ainda mais eficaz devido ao fato de ser resultado da própria produção do aprendiz. A simples comparação entre elementos culturais distintos apresentados pelo professor ou autor do material didático torna o aprendiz um participante passivo no processo de aquisição, o que limita os resultados e aumenta a crítica à outra cultura. Por outro lado, se essa percepção é fruto do trabalho do próprio aprendiz, essa consciência é internalizada e finca raízes mais profundas. (HARGREAVES, 2004, p. 55).

\section{6. (A FALTA DE) DIÁLOGO COM OS ESTUDOS DA TRADUÇÃO}

Em sua dissertação de mestrado, Hargreaves procura, explicitamente, um diálogo com os estudos da tradução e as ricas discussões teóricas travadas nessa área acerca desse complexo fenômeno. Desse modo, o autor se distancia da noção de tradução característica do senso comum - ou seja, a tradução vista como uma atividade de transposição ou

${ }^{13}$ Exemplos práticos para o uso concreto da tradução nesse sentido são apresentados por Rodrigues no referido artigo (2000, p. 25-32).

${ }^{14}$ Entendo que, ao se referir à "cultura", vários autores partem de uma concepção bastante tradicional, descrevendo esse termo praticamente como sinônimo de nação e/ou língua. Embora não compartilhe dessa compreensão de cultura, deixo uma discussão mais aprofundada a esse respeito para um momento futuro.

${ }^{15}$ Vale a pena citar aqui também Claudia Dornbusch que, num livro da área de literatura comparada, aponta que a "contraposição de várias traduções de uma mesma obra [...] pode incitar um enriquecedor diálogo intercultural, na medida em que se observam as variantes pelas quais optaram os tradutores" (2005, p. 73-74). 
transferência de significados, na qual, eventualmente, "diferenças linguísticas ou culturais" possam aparecer. Em outros trabalhos, pode-se constatar uma falta de diálogo com a área dos estudos da tradução, por não haver, por exemplo, menção a trabalhos representativos dessa área nas referências bibliográficas dos autores aqui nomeados. Tal falta de diálogo mostra-se também no uso pouco crítico de termos-chave da área: Checchia, por exemplo, menciona que "não existe sempre equivalência entre as línguas" (2002, p. 127), sem mencionar a problematização realizada na área dos estudos da tradução nas últimas décadas em relação a esse conceito ${ }^{16}$. Já Hargreaves - mais cauteloso no uso de termos polêmicos - com referência a obras representativas da área dos estudos da tradução, destaca que "equivalência" é um "conceito dos mais discutíveis no âmbito da tradução, que costuma levantar a questão da fidelidade" (2004, p. 33).

Welker é outro autor cuja argumentação sugere uma concepção tradicional de tradução: ao se referir ao trabalho tradutório profissional, salienta que o tradutor "só pode traduzir adequadamente se compreendeu o texto de partida, e só pode compreender verdadeiramente se levar em consideração a situação de comunicação” (2008, p. 5). Só seria possível "compreender verdadeiramente" um texto se este tivesse um significado inerente e estável que pudesse ser compreendido de uma forma "correta". Cito uma passagem de um artigo de Rosemary Arrojo para ilustrar que essa concepção de significado que permitiria uma "compreensão verdadeira" tem sido colocada em xeque na área dos estudos da tradução, já há algum tempo:

A possibilidade desse resgate de significados estáveis é pressuposta pela grande maioria do conhecimento produzido pelo homem ocidental e permeia, naturalmente, todas as nossas concepções clássicas de linguagem. É, entretanto, na área de teoria da tradução que as questões implícitas pela aceitação da possibilidade da "compreensão" em moldes logocêntricos são particularmente problemáticas. (ARROJO, 2003, p. 68).

A descrição que encontramos no Quadro Comum Europeu para o Ensino de Línguas da pretendida habilidade dos aprendizes de "transmitir todo o conteúdo e as informações de maneira completa, clara, fluente e estruturada" (GLABONIAT et al. 2005, p. 211) também revela o embasamento em uma concepção tradicionalista de tradução que percebe o texto como um rol, com um "conteúdo" que poderia ser "transmitido" de maneira "completa" para outra língua.

Hargreaves dialoga com os estudos da tradução e com os estudos culturais e desenvolve, consequentemente, uma reflexão mais complexa e em sintonia com abordagens atuais dessas áreas. Ele destaca a importância de se posicionar teoricamente antes de se referir a certos termos centrais do pensamento contemporâneo: "Antes de dar início à análise da relação entre cultura e língua, é fundamental definir os conceitos desses dois termos", pois ambos "permitem mais de uma interpretação, muitas das quais perfeitamente aceitáveis" (2004, p. 15). Também em relação ao termo "tradução", Hargreaves evidencia que foi além da concepção do senso comum: "anteriormente considerada uma atividade essencialmente lingüística, a tradução passou a ser vista como fenômeno interdisciplinar, o que reforça sua ligação com estudos culturais" (2004, p. 33).

\footnotetext{
${ }^{16}$ Cf., por exemplo, House (2001).
} 
Trab. Ling. Aplic., Campinas, 50(1), Jan./Jun. 2011

Embora não concorde com as referências indiscriminadas de Hargreaves a estudiosos da tradução de vertentes teóricas muito diversas, sem explicar ou justificar essa justaposição (por exemplo, de teóricos como Rosemary Arrojo, George Steiner, Eugene Nida e Katharina Reiss), vejo no trabalho desse autor o primeiro passo importante para um diálogo entre o ensino de língua estrangeira, os estudos culturais e a tradução, considerando esta última uma "atividade comunicativa" que deveria ser "integrada no resto do programa de ensino" de línguas estrangeiras (2004, p. 59). O trabalho de Hargreaves representa, no mínimo, um ponto de partida inspirador para se pensar a tradução como atividade didática que objetive uma postura crítica dos aprendizes com relação à língua e à cultura, pois o autor procura evitar simplificações anacrônicas de conceitos teóricos centrais. Algo semelhante - embora em extensão menor devido ao tamanho do trabalho - vale para o artigo de Hinojosa e Lima (2008), autores que, partindo de uma ótica bakhtiniana, destacam a tradução como uma "ferramenta pedagógica" para "enfatizar a relação língua-cultura" (2008, p. 2), enriquecendo essa discussão ao chamarem a atenção para a polissemia terminológica do conceito de cultura - outro conceito fundamental, porém pouco especificado pelos outros autores acima mencionados.

\section{CONCLUSÃO}

No meu entender, a falta de clareza argumentativa e terminológica que apontei nos trabalhos acima mencionados pode ser compreendida, pelo menos em parte, como resultado da falta de diálogo da área de ensino de língua estrangeira com os estudos da tradução, que, há algumas décadas, vem colocando em questão a visão do senso comum a respeito do processo tradutório. É justamente esse senso comum que parece fundamentar, no entanto, vários dos trabalhos que abordam o papel da tradução no ensino de línguas estrangeiras. Um diálogo com as reflexões oriundas da área acadêmica que se dedica centralmente ao estudo desse complexo processo de (re)criação linguístico e cultural que é traduzir poderia, no mínimo, ser frutífero para a área de ensino de línguas estrangeiras sobretudo se o objetivo é uma discussão mais aprofundada sobre os diversos papéis que a tradução, nas suas diferentes formas, pode cumprir no processo de ensino/aprendizagem de uma língua estrangeira.

É importante ressaltar ainda que não pretendo sugerir que reflexões teóricas sobre a complexa atividade de traduzir deveriam entrar no currículo ou planejamento das aulas no ensino de línguas estrangeiras. Acredito, não obstante, que aqueles que se dedicam em nível acadêmico - ao estudo do papel da tradução no ensino de línguas estrangeiras poderiam contribuir para discussões mais esclarecedoras e ricas sobre esse tema, se levassem em consideração as teorias e os debates que têm sido desenvolvidos na área da tradução nas últimas décadas.

\section{REFERÊNCIAS BIBLIOGRÁFICAS}

ARROJO, R. (1992). O signo desconstruido: implicações para a tradução, a leitura e o ensino. Campinas, SP: Pontes, 2003. 
BOHUNOVSKY - A tradução no ensino de línguas: vocabulário...

AZENHA JR., J. (2006). O lugar da tradução na formação em letras: algumas reflexões. Cadernos de Tradução. v. 17 , n. 1 , p. $157-188$.

BUTZKAMM,W.(2004).LustzumLehren,LustzumLernen:EineneueMethodefürdenFremdsprachenunterricht. Tübingen, Basel: A. Francke Verlag.

CARVALHO NETO, G. L. (2007). de Sprachmittlung und der DaF-Unterricht nach GER. Projekt - Revista dos professores de alemão no Brasil. n. 45, p. 57-62.

CHECCHIA, R. L. T. (2002). O retorno do que nunca foi: O papel da tradução no ensino de inglês como língua estrangeira. (Dissertação) - Mestrado em Linguística Aplicada, Departamento de Línguas Estrangeiras e Tradução, Universidade de Brasília, Brasília.

DORNBUSCH, C. (2005). A literatura alemã nos trópicos: uma aclimatação do cânone nas universidades brasileiras. São Paulo: Annablume.

GLABONIAT, M. (2005). et al. Profile deutsch - Gemeinsamer Europäischer Refernzrahmen. Berlin, München: Langenscheidt.

GNUTZMANN, C. (2000). Mensch, be carful! Ein Plädoyer zur Arbeit mit mehrsprachigen Texten im Sprach(en) unterricht. Fremdsprache Deutsch - Übersetzen im Deutschunterricht. Stuttgart, Klett, Heft 23, p. 33-39.

HARGREAVES, L. E. S. (2004. Além da língua: Tradução e consciência crítica de cultura no ensino de línguas estrangeiras. (Dissertação) - Mestrado em Linguística Aplicada, Departamento de Línguas Estrangeiras e Tradução, Universidade de Brasília, Brasília.

HINOJOSA, F. R.; LIMA, R. (2008). A tradução como estratégia de interculturalidade no ensino de língua estrangeira. Bocc. Biblioteca On-line de Ciências da Comunicação, v. 1, p. 1-10, Disponível em:

$<$ www.bocc.ubi.pt/pag/lima-hinojosa-traducao-estrategia-interculturalidade.pdf $>$. Acesso em: $15 \mathrm{dez}$. 2008.

HOUSE, J. (2001). Übersetzen und Fremdsprachenunterricht. In: HELBIG, Gerhard; GÖTZE, Lutz; HENRICI, Gert (org.). Deutsch als Fremdsprache - Ein internationales Handbuch (vol. 1). Berlim, Nova Yorque: de Gruyter, p. 258-268.

JAKOBSON, R. (1969). Aspectos lingüísticos da tradução. Lingüística e Comunicação. São Paulo: Cultrix.

KÖNIGS, F. G. (2000). Übersetzen im Deutschunterricht? Ja, aber anders!. Fremdsprache Deutsch - Übersetzen im Deutschunterricht. Stuttgart: Klett, Heft 23, p. 6-13.

. (2001). Übersetzen. In: HELBIG, Gerhard; GÖTZE, Lutz; HENRICI, Gert; KRUMM, Hans-Jürgen (org.). Deutsch als Fremdsprache. Ein internationales Handbuch (vol. 2). Berlim, Nova Yorque: de Gruyter, p. 955-962.

NOWAK, E. (2000). Einsprachig? - Zweisprachig? Übersetzung als Mittel der Semantisierung von Wortschatz. Fremdsprache Deutsch - Übersetzen im Deutschunterricht. Stuttgart, Klett, Heft 23, p. 14-18.

RODRIGUES, C. (2000). Warum hast du so und nicht anders übersetzt? Übersetzen als Übungsform: Praktische Beispiele aus dem brasilianischen Deutschunterricht. Fremdsprache Deutsch - Übersetzen im Deutschunterricht. Stuttgart: Klett, Heft 23, p.25-33.

ROMANELLI, S. (2006). Traduzir ou não traduzir em sala de aula? Eis a questão. Inventário - Revista dos Estudantes do Programa de Pós-graduação em Letras e Lingüística da Ufba, Salvador, n. 05. Homepage: www.inventario.ufba.br/05/05sromanelli.htm; (ISSN/ISBN: 16791347). Acesso em: 10 de dez. 2008. 
SÁNCHEZ-NIETO, T. (/2000). Für unsere Abteilung suchen wir... Übersetzungsübungen mit der Textsorte 'Stellenanzeigen' im berufsbildenden Deutschunterricht. Fremdsprache Deutsch - Übersetzen im Deutschunterricht. Stuttgart: Klett, Heft 23, p. 47-52.

WELKER, H. A. (2004). Traduzir frases isoladas na aula de lingua estrangeira - por que não? Brasília: Horizontes. Disponível em: <www.unb.br/il/let/welker/tradfras.doc>. Acesso em: 11 dez. 2008.

Recebido: 06/04/2009

Aceito: 30/06/2010 
